\title{
O sagrado em Mia Couto e Manoel e Barros
}

\author{
Maria Auxiliadora Fontana Baseio ${ }^{1}$
}

RESUMO: A literatura assume contornos singulares nas franjas dos núcleos hegemônicos. Brasil e África são territórios marcados por uma complexa tensão entre elementos genuínos e elementos impostos pela colonização. Irmanar essas experiências fronteiriças é a nossa tentativa neste texto de Literatura Comparada, no qual desfilarão reflexões sobre as fulgurações do sagrado como possibilidades de fortalecer as raízes identitárias. Centramos nossa análise em Mia Couto e Manuel de Barros.

ABSTRACT: Literature assumes singular contours in the fringes of the hegemonic countries. Brazil and Africa are territories marked by complex tension between genuine elements and elements imposed by the colonization. In this text of Comparative Literature, we aim to bring these bordering experiences together, by reflecting on sacred elements as significant source to fortify the identity. We will present a comparative reading of Mia Couto and Manuel de Barros works.

PALAVRAS-CHAVE: Manoel de Barros; Mia Couto; sagrado; identidade.

KEY-WORDS: Manoel de Barros; Mia Couto; sacred elements; identity.

A princípio, cabe-nos esboçar algumas considerações sobre o conceito de sagrado tal como será entendido no contexto deste trabalho.

É no seio da Antropologia Religiosa, como parte de uma antropologia simbólica que o tema encontra ressonância. O sagrado vem sendo considerado como uma realidade antropológica, ou seja, como algo especificamente humano, uma vez que todas as sociedades parecem ter desenvolvido esse tipo de noção, compreendida como distinta do campo do religioso institucionalizado. Por estudar o homem, esse campo da Antropologia pode beneficiar outros domínios do conhecimento - o que nos possibilita aproximá-lo da Literatura e com ela entrelaçá-lo em uma proposta interdisciplinar.

Fundamentaremos nossa análise do sagrado em Mircea Eliade, para quem tanto o sagrado quanto o profano designam duas modalidades de estar no mundo. O sagrado remete ao que está saturado de ser, de realidade, de perenidade, de eficácia, fonte de vida e de fecundidade.

\footnotetext{
${ }^{1}$ Doutoranda em Estudos Comparados de Literaturas de Língua Portuguesa, FFLCH-USP. Pesquisa: $O$ sagrado em Manoel de Barros e Mia Couto. E-mail: dorafada@ig.com.br
} 
Mircea Eliade apresenta o espaço sagrado como forte, significativo, não homogêneo, como aquele que aponta quebras, rupturas, manifesta uma realidade absoluta capaz de fundar ontologicamente o mundo. Para o autor: "Todo espaço sagrado implica uma hierofania, uma irrupção do sagrado que tem por resultado destacar um território do meio cósmico envolvente e torná-lo qualitativamente diferente.” (ELIADE, s.d., p.40)

Já o espaço profano traduz-se como neutro, homogêneo, nele nada é passível de diferenciação qualitativa, nada há de absoluto, ele é sempre relativo, os pontos centrais não possuem estatuto ontológico único. Constitui-se o espaço profano como uma série de fragmentos relativamente neutros pelos quais o homem transita coagido por suas obrigações. Enquanto ao profano pertence o ordinário, ao sagrado pertence o extraordinário.

Vale ressaltar que, no mundo atual, em que se valoriza excessivamente a razão e o modo material de existência, a sacralidade esconde-se, camufla-se nas dobras do profano. É com esse olhar "religado" com o sagrado do mundo que propomos nossa leitura de $O$ gato $e$ o escuro, do moçambicano Mia Couto, e de Poeminhas pescados numa fala de João, do brasileiro Manuel de Barros.

O livro Poeminhas pescados numa fala de João compõe-se de 10 poemas, brilhantemente ilustrados por Ana Raquel, que colocam o leitor em viagem sagrada, entre o mirar terreno da janela do trem (cujos trilhos percorrem a parte inferior de todas as páginas do livro) e o olhar aéreo no dorso das andorinhas (que atravessam o espaço superior das páginas). É assim, com esse espírito de andarilho, que o leitor pisa a Terra, mergulha nas águas, transubstancia-se em peixe, pato, cobra, pássaro, encontra-se com a Noite, escuta o rio interior, ganha asas e alça vôo de andorinha a explorar o vento.

O livro O Gato e o Escuro, de Mia Couto, admiravelmente ilustrado por Danuta Wojeiechowska, enreda o leitor em sua prosa poética, arrastando-o para "o lado de além da claridade". Nessa "trespassagem" imaginária do claro ao escuro, do dia para a noite, o leitor cruza as fronteiras do mundo ordinário e, em estado de enlevo, penetra no reino do extraordinário - percurso sagrado por excelência.

Sagrado, também, é o ato criador desses autores de texto verbal e visual; sagrado é o ato recriador da leitura, por serem ambos cosmogônicos por princípio, pois repetem, ritualmente, a criação primeira.

Tanto em Manoel de Barros quanto em Mia Couto, o leitor entra em contato com o transcendente por meio da natureza. Nas duas obras, esta se manifesta qualitativamente 
diferente da forma como se apresenta na vida ordinária. Verificamos que, em "Manoel de Barros, "A Noite caiu da árvore"; "o boi piou cheio de folhas com água"; em Mia Couto, "o gato preto"estava "enroscado do outro lado do mundo"; o escuro se encolheu, ataratonto".

Ambos os autores valem-se das combinações de imagens típicas do pensamento mágico e mítico, grávido de maravilhoso, que caracteriza esse narrar artístico primordial do homem, construído por metamorfoses, pelo impossível: em Manoel de Barros - "João foi na casa do peixe", "meu bolso teve um sol com passarinhos", " A Noite caiu da árvore. Maria pegou ela pra criar e ficou preta", "o sapo de pau virou chão", "o cocô de capiravas era rodelinhas - bola de gude",; ou em Mia Couto - "Certa vez, inspirou coragem e passou uma perna para o lado de lá, onde a noite se enrosca a dormir", "Só quando desaguou na outra margem do tempo ele ousou despersianar os olhos", "E os olhos do escuro se amarelaram". Enfim, em ambos os autores, o universo apresenta-se como plástico e fluido, pondo em relevo as qualidades do sentir: a intuição, a emoção, a sensibilidade, a experiência concreta - características do pensamento mágico e de um estar no mundo concebido como sagrado.

Manoel de Barros pesca os poemas da fala de João e, por isso, traz as marcas dessa oralidade: onomatopéias: tibum, pan, pum; construções sintáticas inusitadas: "ficou todo molhado de peixe", "eu se chorei"; desvios da norma culta: "tinha dois pato grande". "Maria pegou ela" "a gente pega ele pelo rabo; construções próprias da fala infantil feitas por analogia com os tempos verbais regulares: "Veio Maria-preta fazeu três araçás pra mim", "você viu um passarinho abrido"; uso de aumentativo e diminutivo para conferir dramaticidade ao discurso e ampliar o traço heróico do "contador": de dia apareceu uma cobrona debaixo de João. Eu matei a boca pequenininha daquela cobra"; regionalismos: "Ninguém não tinha um rosto com chão perto", "minha boca estava seca igual do que uma pedra"; repetições: "meu lambarizinho/escapuliu-ele priscava/priscava".

Mia Couto propõe travessia tanto no plano do conteúdo quanto no plano da expressão.Assim como o gato rompe a fronteira do conhecido, do permitido, do estabelecido, do uso ordinário do verbo, rompe também o autor, no plano da forma, usando expressões que cruzam as fronteiras do esperado, da norma-padrão e atingem o inesperado, o imprevisível: construções sintáticas inusitadas: "gostava passear-se"; neologismos: "trespassagem", "namoriscando", pirilampejavam", "tiquetaqueava", "noitidão,"

\footnotetext{
${ }^{2}$ É característica de Manoel de Barros valorizar elementos escatológicos para construir sua cosmogonia.
} 
"despersianar"; "gateza"; "arcoiriscando" "estremolhado"; uso do vocativo revelando a conversa com o leitor e resgatando o papel do contador: "Vejam, meus filhos", "conta a mãe", Aconteceu assim, "faz mais de conta ainda","Adivinham?"

Tanto o brasileiro quanto o moçambicano resgatam, com esses recursos, a tradição oral - marca identitária das duas culturas. Manoel de Barros mostra nos escritos finais de sua obra: "Língua de criança é imagem/ da língua primitiva/ $\mathrm{Na}$ criança fala o índio, a árvore, o vento/ $\mathrm{Na}$ criança fala o passarinho/ $\mathrm{O}$ riacho por cima das pedras soletra os meninos./ $\mathrm{Na}$ criança os musgos desfalam, desfazem-se/ Os nomes são desnomes./ Os sapos andam na rua de chapéu./ os homens se vestem de folhas no mato/ A língua das crianças contam a infância/ em tatibitati e gestos.” Mia Couto, em entrevista a Sophia Beal, em Portugal, março de $2005^{3}$ afirma: "os momentos que eu "estou" escritor são os momentos na minha vida em que tenho uma relação com o mundo, com os outros, com as coisas, com os seres, que é uma relação em que me permite ser criativo, me permite estar num estado de infância e em que estou olhando o mundo como alguém que ainda está se surpreendendo com ele". Ambos devolvem à língua seu estado sagrado de infância: o mitopoético. O poético da linguagem abre múltiplas leituras, faz-se pela analogia, pelas comparações implícitas, pela metáfora, pela metonímia, linguagem que figura o uso "estranhado" do verbo.

A estrutura cíclica que marca as duas obras tornam-nas coesas com a dimensão ritual e sagrada, em que o tempo é circular, a-histórico, reversível, possibilitando o eterno retorno, no dizer de Mircea Eliade (1992).

Em Poeminhas Pescados numa fala de João, é a ilustradora que pesca, com sensibilidade, esse movimento circular sagrado, marcado pelas andorinhas que, entre a capa e a contracapa, voam em círculo, reafirmado pela presença do trem, que sugere a travessia das páginas-vida, e pela composição em espelhamento.

Em $O$ gato e o escuro, o leitor também é convidado a ir e voltar na estória.O movimento cíclico é sugerido, na linguagem verbal, pela fala inicial do narrador: ("Vejam, meus filhos, o gatinho preto, sentado no cimo desta história. Pois ele nem sempre foi dessa cor.”) e pela fala final: ("Então, o gatinho Pintalgato espreitou nessa fenda escura como se vislumbrasse o abismo. Por detrás dessa fenda o que é que ele viu? Adivinham? Pois ele viu um gato preto, enroscado do outro lado do mundo.”). Também fica evidenciado o ritmo

\footnotetext{
${ }^{3}$ http://www.lainsignia.org/2005/marzo/cul_030.htm.
} 
cíclico da natureza pela escolha do sol e da lua, representativos do dia e da noite - espaço da travessia. É um rito natural que se mostra. Simbolicamente, com a noite, rememoram-se as trevas pré-natais, a escatologia, e, com o dia, o nascer do sol, a cosmogonia - para Eliade, movimento sagrado por excelência. Na linguagem visual, esse gesto exemplar ritual, cíclico, é apresentado, metonimicamente, pela ilustração em malhas, pintas e caras de gatos amarelos que se repetem no início e no final do livro em páginas duplas e, na capa e contracapa, em que se repete a imagem do olho. Na contracapa, a metáfora do olhojanela, com a qual a ilustradora iluminadamente traz, ao patamar dos olhos, o teatro do mundo, reiterando o trajeto que leva do visível ao invisível, do ordinário ao extraordinário, do profano ao sagrado, reconhecidos na espessura da existência.

Se pelo sagrado as obras se aproximam, pelo profano elas se diferenciam. Não se pode desconsiderar o caráter histórico das consciências que organizaram as obras, tampouco se pode olvidar a formação social, a ideologia, a cultura em que se insere cada uma delas. Cabe-nos, portanto, analisar que sentido tem a travessia de um gato para a cultura moçambicana? E de imagens da natureza pescadas na fala de João?

É fato que, nas dobras do sagrado, Mia Couto inscreve seu projeto estético e seu projeto político. O gato e o escuro é a forma que esse autor encontrou para revelar o encontro de seu povo com sua cor, com sua etnia, com sua identidade - tão cara aos escritores do pós-colonialismo.

Ao "trespassar" a ordem estabelecida, Pintalgato abraça o sonho da liberdade, da independência, da autodescoberta, lança-se na construção de sua própria identidade. $O$ gato amarelo tem nome. O preto tem cor personificada, o escuro, o negro, etnia que ganha força de ser, na passagem de adjetivo a substantivo. Encarnado em Pintalgato, Mia Couto recusa a domesticação do espírito pela ousadia. Lançando-se à transgressão, em uma realidade em que, por princípio, é inaceitável, Pintalgato torna-se signo da resistência.

A voz moçambicana oferece-nos ao olhar uma África-menina que se permite transgredir; fazendo, assim, entrever a possibilidade de revisão e de reversão de valores instituídos pela colonização. Na "trespassagem" de Mia Couto, espelha-se a travessia do povo africano, iluminado por suas lutas e infinitas iniciações. Pintalgato recusa a obediência, lança-se à descoberta e à liberdade. Transitando entre o real e o imaginário, entre o sol e a lua, no espaço mágico das zonas fronteiriças, toda a transformação libertária torna-se possível. 
Quem olha, olha de algum lugar. Projetado em Pintalgato, Mia Couto observa do cimo, do alto e de longe, vigia, protege, informa, comunica, sonha sua mensagem. Com sua mirada, desperta no leitor a curiosidade de ver para frente e de ver em profundidade realidades existenciais que escapam ao olhar comum.

Mia Couto alinhava as malhas de um tecido imaginário que é próprio de sua cultura de origem: animais, sol, lua, elementos naturais que se coadunam com o mito. No fazer-crer do moçambicano, o encontro do velho e do novo, da mãe e do filho, apresenta um valor caro à cultura africana, que deseja o futuro ciosa de suas tradições. No fio da voz que narra, no suporte aglutinador da língua, à revelia de toda norma, abrem-se caminhos e desenhos do que se arquiteta como grito pela invenção silenciosa de palavras.

Como já enunciamos, Pintalgato sai a passeio pela "linha onde o dia faz fronteira com a noite", atravessa a luz, vence o limite, penetra no escuro disforme - "a noitidão" e deságua na outra margem do tempo-interior-imaginação, até retornar ao cimo da história. Junto a ele, peregrina o leitor: de ser passa a não-ser até engendrar-se em novo ser. Eis a narrativa-travessia. Eis um novo povo que se forma, capaz de atravessar sua própria história e, no cimo, ascender de objeto a sujeito. Ensina Guimarães Rosa pela voz de Riobaldo: "Qual é o caminho certo da gente? nem para frente nem pra trás: só para cima." (ROSA, 1986, p.78)

Manoel de Barros resgata, na fala de João, imagens tradicionalmente associadas ao Brasil. Reconciliada com o movimento da natureza, sua poesia ganha chão. Desfilam, na paisagem poética verbal e visual, a fauna, a flora e a alma de um Brasil-criança, virgem de toda exploração. Sons propagam aberturas de cor e cheiro da nossa terra, imagens que se afinam com o compasso de nossa paisagem natural. Por entre as folhas das árvores, por entre os cantos dos pássaros, sussurra a voz de nossos ancestrais, nossa fala mais genuína. Ouve-se o sussurrar de nosso olhar primeiro, primitivo, inaugural, coeso com a natureza. Por isso, sua poesia é resistência, recusa à exploração do chão e ao desmatamento da alma brasileira. Tudo isso se pesca na fala de João, em uma língua que, por recusa, reverte a escrita. Com ela, inscreve-se uma gramática do chão brasileiro. Manoel de Barros escreve com olhos sensíveis: vê, aproxima-se das palavras, espreita seus significados, descobre sentidos inusitados.Com onomatopéias, o poema ganha som, com metáforas e metonímias, o poema ganha cor, forma, visibilidade, com as combinações sinestésicas, o poema ganha cheiro, toque, ganha sentidos. Ouve-se, nas frestas silenciosas de seu mosaico poético, um grito em favor de uma nação que, a cada dia, busca reinventar-se. Mostra ao leitor o 
milagre do chão, a maravilha do que não se esgota, o encanto do que permanentemente se refaz. Transubstancia homem em natureza, devolve-lhe a origem, recolocando-o em estado de graça.

A natureza - ventre poético - fecunda renovação e libertação. Ela é a matéria que compõe o sonho diurno do poeta. ${ }^{4}$ Dela nasce o encantamento da letra, os deslimites do verbo, o silêncio ressabiado das peraltagens poéticas. O poeta inaugura um mundo outro, inteiramente distinto do ordinário. Sua linguagem põe-se rasteira, próxima da coisa, concreta, portanto, simples, um tanto vizinha da língua adâmica, por isso seus versos são livres, soltos, desarticulados, distantes da linguagem adulta, culta, pensada, longe do estabelecido e próxima do bem antes da colonização. Com Manuel de Barros, a poesia é devolvida às suas origens e nos devolve as origens, recuperando as múltiplas possibilidades que nossa língua tem de abrir ao homem a visão do extraordinário.Com seus "despropósitos", a poesia de Manuel de Barros deita raízes em solo brasileiro, põe a imaginação do leitor em revoada, para que, de fato, amanheça.

À guisa de conclusão, tanto a viagem proposta por Manuel de Barros quanto a "trespassagem" anunciada por Mia Couto exprimem menos uma vontade de deslocar fisicamente e muito mais uma sede de descobrir verdades.

Viagem é busca, é travessia, quem está em viagem não está pronto, está em processo, em processo de busca de si, do novo e da própria identidade.Viagem é signo de aventura, de procura, motivada pela insatisfação, orientada para a busca de si. Literatura é viagem-travessia, é viagem sagrada que se faz pelo sonho nas curvas do Imaginário.

Com a literatura de Manoel de Barros e Mia Couto, viajamos para um tempo paradisíaco de graça anterior à domesticação da natureza pelo homem, escavamos um tempo mítico, revisitamos os subterrâneos do sonho - individual e coletivo. A percepção animista que reveste a arte literária desses escritores é fonte de conhecimento e de transformação, de recusa e de reconciliação.

Ambos auscultam a natureza interna e externa, ouvem o sussurrar do cosmos e plasmam essas sensações em imagens, entoam os movimentos da alma, em fulgurações sagradas - e é isso que nos arrebata. Ambos deixam entrever, no novo da aparência, o

\footnotetext{
${ }^{4}$ Conforme Benjamin Abdala Junior, em De Vôos e Ilhas, p.18: "é o sonho de quem procura novos horizontes [...] Essa atitude é mais adequada do que o sonho noturno, que teima obsessivamente em olhar para trás, melancolicamente contemplando as ruínas.” - inspirado em Ernst Bloch.
} 
primordial e eterno da essência. Os autores resgatam o poder originário da linguagem de nomear, de compreender a natureza e, nesse ato mágico, resgatam o "ser" da poesia de que fala Alfredo Bosi ${ }^{5}$, para bem além do seu mísero existir. Com esses dois autores, o poético não sobrevive, ele revive em plenitude.

A contrapelo de dogmáticos discursos, o sagrado, marca que universaliza a arte, semente que faz nascer literatura, nas duas obras analisadas, revela-se como o reino da transgressão. Essa modalidade de estar no mundo, diversa da repetitiva vida cotidiana, abre possibilidades fecundas à África e ao Brasil, herdeiros do mito e do místico, de reencontrarem suas identidades. O sagrado, aqui, insurge-se como modo libertário de ler a existência. Pelas dobras do sagrado, os dois autores não só rememoram miticamente a origem da terra-mãe, mas também projetam o sonho da comunhão do homem com a natureza, do homem consigo mesmo e do homem com os outros homens. Unidos pela mesma pátria: a língua, passageiros da mesma viagem-travessia: a arte da palavra, tanto o moçambicano Mia Couto quanto o brasileiro Manoel de Barros enlaçam, nas fulgurações do sagrado, suas reinvenções do porvir. Duas são as culturas: o sonho é Um.

\section{Referências bibliográficas}

ABDALA JUNIOR, Benjamin. De vôos e Ilhas: literatura e comunitarismos. São Paulo: Ateliê Editorial, 2003.

BARROS, Manoel. Poeminhas pescados numa fala de João. 2. ed. Rio de Janeiro: Record, 2001. BOSI, A. O ser e o tempo da poesia. São Paulo: Cia das Letras, 2000.

COUTO, Mia. O gato e o escuro. 2 ed. Lisboa: Editorial Caminho, 2001.

ELIADE, Mircea. Imagens e símbolos. trad. Sônia Cristina Tamer. São Paulo, Martins

Fontes, 1996.

—. Mito do eterno retorno. trad. José Antônio Ceschin. São Paulo, Mercuryo, 1992.

—. Mito e realidade. trad. Pola Civelli. 4.ed., São Paulo, Perspectiva, 1994.

—. O sagrado e o profano - a essência das religiões. Trad. Rogério Fernandes.

Lisboa, Livros do Brasil, s.d.

—. Tratado de história das religiões. São Paulo, Martins Fontes, 1993.

. O Conhecimento Sagrado de todas as Eras. Trad.Luiz L. Gomes. São Paulo, Mercuryo, 1995.

ROSA, Guimarães. Grande Sertão: Veredas. Rio de Janeiro: Nova Fronteira, 1986.

Sites: http://www.lainsignia.org/2005/marzo/cul_030.htm.

\footnotetext{
5 "Essas formas estranhas pelas quais o poético sobrevive em um meio hostil ou surdo não constituem o ser da poesia, mas apenas o seu modo historicamente possível de existir no interior do processo capitalista" (BOSI, A. 2000, p.165).
} 